\section{ORIGINAL RESEARCH}

T. Gunnarsson

F.C. Tong

P. Klurfan

C.M. Cawley

J.E. Dion

\title{
Angiographic and Clinical Outcomes in 200 Consecutive Patients with Cerebral Aneurysm Treated with Hydrogel-Coated Coils
}

\begin{abstract}
BACKGROUND AND PURPOSE: Denser coil packing in intracranial aneurysms is believed to result in lower recanalization rates. Hydrogel-coated expandable coils (HydroCoil) improve volumetric packing of aneurysms in animal models and clinical studies, but data from large clinical series are limited. The objective of this retrospective analysis was to analyze immediate and follow-up angiographic results as well as complications in a large consecutive series of patients treated with HydroCoils at a single institution.
\end{abstract}

\begin{abstract}
MATERIALS AND METHODS: Retrospective analysis was performed of periprocedural complications, immediate and follow-up angiograms, and retreatments of the first 200 consecutive intracranial aneurysms treated at Emory University Hospital.

RESULTS: One hundred eighty-seven patients with 200 intracranial aneurysms were treated with HydroCoils during a 3-year period. Immediate angiograms showed complete aneurysmal obliteration in $58.4 \%$ of small aneurysms and $42.7 \%$ of large aneurysms. Periprocedural complications included early rebleeding and thromboembolic events resulting in permanent neurologic morbidity and mortality in $6 \%$ of cases. Follow-up angiography during an average of 16.3 months demonstrated recanalization in $17.7 \%$ of small aneurysms and $28.6 \%$ of large aneurysms, requiring retreatment in $6.3 \%$ and $19.0 \%$ of cases, respectively. During the same time period, there was delayed angiographic improvement in aneurysm obliteration in $26.6 \%$ of small aneurysms and $26.2 \%$ of large aneurysms.
\end{abstract}

CONCLUSIONS: First-generation HydroCoil treatment of intracranial aneurysms has a favorable rate of recanalization compared with most large series of pure platinum coils with similar complication rates.

$\mathbf{T}$ reatment of intracranial aneurysms with bare platinum coils was shown to improve outcome in patients with ruptured cerebral aneurysms compared with surgical clipping in a large randomized multicenter trial. ${ }^{1}$ Concern remains regarding the long-term durability because a significant proportion of coiled aneurysms can recanalize, with a subsequent rerupture rate of $2.6 \%$ at 1 year. ${ }^{2}$ The degree of luminal packing has been found to be inversely proportional to the likelihood of recurrence, with more tightly packed aneurysms being less likely to recur. ${ }^{3}$ Hydrogel-coated platinum coils (HydroCoil; MicroVention, Aliso Viejo, Calif) were designed to increase volumetric packing of aneurysms. ${ }^{4}$ After blood contact, the HydroCoil gel coating expands to a diameter 5-11 times that of a standard 0.010 inch platinum coil, allowing potentially improved packing attenuation. ${ }^{4}$ The capacity of HydroCoils to increase packing attenuation has been demonstrated in animal models and humans, but experience in large clinical series is limited. ${ }^{4-11}$ We report a large single-center experience with the use of HydroCoils, focusing on immediate angiographic results, periprocedural complications, and midterm angiographic follow-up.

Received October 23, 2008; accepted after revision April 27, 2009

From the Division of Neurosurgery (T.G., P.K.), McMaster University Hospital, Hamilton, Ontario, Canada; and MBNA Stroke Center (F.C.T., C.M.C., J.E.D.), Emory University, Atlanta, Ga.

MicroVention provided funding for the cost of travel and accommodations for T.G. and P.K. but has been uninvolved in the collection and tabulation of the data. J.E.D. is a paid consultant for MicroVention/Terumo.

Please address correspondence to Frank C. Tong, MD, Department of Radiology, Room AG27, Emory University Hospital, Atlanta, GA 30345; e-mail: ftong@emory.edu

DOI 10.3174/ajnr.A1691

\section{Materials and Methods}

\section{Study Design}

Approval for retrospective data collection and analysis was granted by the institutional review board, and imaging and chart review were performed. Records of all consecutive patients treated with HydroCoils at Emory Hospital from October 2002 to October 2005 were reviewed, including clinic notes, procedure notes, and discharge summaries along with pertinent neuroimaging. Patients undergoing planned parent-vessel sacrifice were excluded from the study. A data base of the first 200 consecutive cases was created, and a retrospective analysis was performed.

\section{General Technical Considerations}

There were no strict inclusion/exclusion criteria, and HydroCoils were used at the discretion of the surgeon. Generally, the HydroCoils were considered to be mechanically stiffer than identically sized bare platinum coils, requiring more space within the aneurysm lumen. Therefore, HydroCoils were used when there was thought to be adequate luminal volume to accommodate the relatively stiffer coil. All patients were treated under general anesthesia and fully heparinized with $5000 \mathrm{U}$ intravenously administered at the beginning of the procedure, with subsequent 1000-U redosing at 1-hour intervals. After a number of thromboembolic events early in the experience consisting primarily of clot on coil, subsequent patients also received acetylsalicylic acid $325 \mathrm{mg}$ either orally (PO) or per rectum before placement of the initial coil. When stent assist was used, patients also received a 375-mg PO loading dose of clopidogrel, unless they had been taking the standard 75-mg dose for $>3$ days before stent implantation. Generally, surgeons used the largest microcatheter that could be safely deployed in the aneurysm for maximal compatibility with the HydroCoils. The aneurysm was typically framed with a bare platinum fram- 
ing coil followed by filling coils consisting of both HydroCoils and bare platinum coils. Typically, softer finishing coils were used at the end of the procedure as deemed necessary by the surgeon, though HydroCoils were increasingly used as finishing coils toward the end of the series.

\section{Clinical and Angiographic Features}

Patient characteristics, including sex, age, and mode of presentation, were documented along with clinical grade by using the Hunt and Hess scale and the Fisher CT grading scale for patients with subarachnoid hemorrhage (SAH). ${ }^{12,13}$ Aneurysm location, maximal diameter, and immediate final angiographic treatment results were studied by using the classification of Roy et al, ${ }^{14}$ in which class 1 is complete aneurysm occlusion, class 2 is residual neck filling, and class 3 is residual aneurysm filling. The lengths of both HydroCoil and bare platinum coils were documented. Any adjunctive techniques, such as balloon remodeling or stent-assisted coiling, were also recorded. Intraprocedural, postprocedural, and follow-up angiograms were studied to assess aneurysm recurrence and recanalization. Recurrence was defined as a change in aneurysm filling from class 1 to class 2 , class 2 to class 3 , or class 1 to class 3 . In cases in which the initial treatment results were class 3 , any increase in aneurysm filling was also considered a recurrence.

\section{Complications}

Any periprocedural complication that was a potential result of endovascular coiling was documented along with its clinical consequences, including the presence or absence of permanent disability. This included late complications such as rebleeding, delayed parenchymal hemorrhage, development of hydrocephalus in unruptured aneurysms, and aseptic meningitis.

\section{Results}

\section{Data Quality}

In general, very detailed procedure notes with documentation of the indication for the treatment, techniques, periprocedural complications, and materials used were available for each patient. The neuroimaging was of sufficient quality, allowing definitive analysis of the angiographic results. The final posttreatment angiogram was studied in 2 projections but not with $3 \mathrm{D}$ rotational angiography. For clinical grading, the clinical condition of the patients on admission and on discharge was well documented. For documentation of the initial Fisher grade, CT scans from the referring hospital were not always available, but in most cases, a detailed written interpretation from a neuroradiologist was available.

\section{Patients' Characteristics}

Between November 20, 2002, and November 20, 2005, 200 intracranial aneurysms were treated with endovascular coiling by using HydroCoil as the only embolic material or in combination with other bare platinum coils at the Emory Hospital. There were 139 females and 48 males (mean age, 54 years; range, 4-87 years). There were 104 unruptured or recanalized and 96 ruptured aneurysms, with a mean maximal diameter of $9.3 \mathrm{~mm}$ (range, 3-25 mm). Table 1 shows the characteristics of patients with ruptured aneurysms, and Table 2 shows the aneurysm locations.

\begin{tabular}{|c|c|c|c|c|}
\hline & Mean & Minimum & Maximum & Median \\
\hline Age (yr) & 54 & 4 & 87 & 54 \\
\hline Male & 48 & & & \\
\hline Female & 139 & & & \\
\hline Unruptured & 104 & & & \\
\hline Ruptured & 96 & & & \\
\hline Hunt and Hess grade & 2.94 & 1 & 5 & 3 \\
\hline Fisher grade & 2.77 & 1 & 4 & 4 \\
\hline
\end{tabular}

\begin{tabular}{|c|c|c|c|}
\hline Artery Location & Left & Right & Total $(\%)$ \\
\hline Anterior circulation & & & $151(75.5)$ \\
\hline Ophthalmic & 25 & 10 & $35(17.5)$ \\
\hline Posterior communicating & 17 & 16 & $33(16.5)$ \\
\hline Anterior communicating & & & $20(10)$ \\
\hline Superior hypophyseal & 15 & 8 & $23(11.5)$ \\
\hline Internal carotid* & 8 & 11 & $19(9.5)$ \\
\hline Middle cerebral & 5 & 5 & $10(5)$ \\
\hline Carotid termination & 3 & & $3(1.5)$ \\
\hline Anterior choroidal & 2 & 1 & $3(1.5)$ \\
\hline Pericallosal & 2 & 1 & $3(1.5)$ \\
\hline Anterior cerebral & 1 & 1 & $2(1)$ \\
\hline Posterior circulation & & & $49(24.5)$ \\
\hline Basilar tip & & & $37(18.5)$ \\
\hline Superior cerebellar & & & $5(2.5)$ \\
\hline Vertebrobasilar junction & & & $2(1)$ \\
\hline Posterior cerebral & & & $2(1)$ \\
\hline Basilar trunk & & & $1(0.5)$ \\
\hline $\begin{array}{l}\text { Posterior inferior } \\
\text { cerebellar }\end{array}$ & & & $1(0.5)$ \\
\hline Vertebral & & & $1(0.5)$ \\
\hline
\end{tabular}

* Includes the cavernous/carotid cave/paraclinoid.

\section{Treatment and Immediate Angiographic Results}

Balloon assist was used in 59 (29.5\%) patients and a Neuroform (Boston Scientific, Natick, Mass) stent was used in 30 (15\%) of patients. The mean overall percentage length of HydroCoils relative to the total length of coils implanted could be calculated for 164 of the 200 aneurysms treated overall. The overall mean percentage HydroCoil length was 58\% (5\%-100\%), with a median of 59\%. Immediate postembolization angiograms showed complete obliteration in $58.4 \%$, residual neck in $28.0 \%$, and residual aneurysm filling in $13.6 \%$ for the 125 small aneurysms $(<10 \mathrm{~mm})$. In the 75 large aneurysms $(10-25 \mathrm{~mm}), 42.7 \%$ were completely obliterated, $34.7 \%$ had residual neck, and $21.4 \%$ had residual aneurysm filling. For both small and large aneurysms combined, there was complete obliteration in 53.8\%, residual neck in $29.6 \%$, and residual luminal filling in $16.6 \%$ overall. There was also unintentional parent-vessel occlusion during treatment of 1 large aneurysm.

\section{Recanalization and Retreatment Rate}

Follow-up angiograms at a minimal 5-month interval were available for $121(60.5 \%)$ aneurysms, with a mean follow-up of 16.3 months. The percentage HydroCoil length could be calculated for 115 of these 121 patients. A total of 26 recurrences were identified for an overall rate of $21.5 \%$. These data were further subdivided into small $(<9 \mathrm{~mm})$ and large $(10-25 \mathrm{~mm})$ aneurysms and are summarized in Table 3 . The recurrence rate was $17.7 \%$ for small aneurysms 


\begin{tabular}{|c|c|c|c|c|c|}
\hline & No. Patients & $\begin{array}{l}\text { No. Patients in } \\
\text { Subgroup (\%) }\end{array}$ & $\begin{array}{c}\text { Average } \% \text { HydroCoil } \\
\text { Length }(\%)\end{array}$ & $\begin{array}{l}\text { Average Maximal } \\
\text { Diameter }(\mathrm{mm})\end{array}$ & $\begin{array}{l}\text { Dome-Neck } \\
\text { Ratio }\end{array}$ \\
\hline All Patients & $121(100 \%)$ & & 55 & 9.0 & 1.82 \\
\hline Recurrence & & $26(21.5)$ & 64 & 10.4 & 1.85 \\
\hline No recurrence & & 95 (78.5) & 53 & 8.6 & 1.8 \\
\hline Small aneurysms & $79(65.3 \%)$ & & & & \\
\hline Recurrence & & $14(17.7)$ & 58 & 7.0 & 1.56 \\
\hline No recurrence & & 65 (82.3) & 51 & 6.6 & 1.56 \\
\hline Large aneurysms & $42(34.7 \%)$ & & & & \\
\hline Recurrence & & $12(28.6)$ & 70 & 14.3 & 2.11 \\
\hline No recurrence & & $30(71.4)$ & 58 & 13.0 & 2.26 \\
\hline
\end{tabular}

A

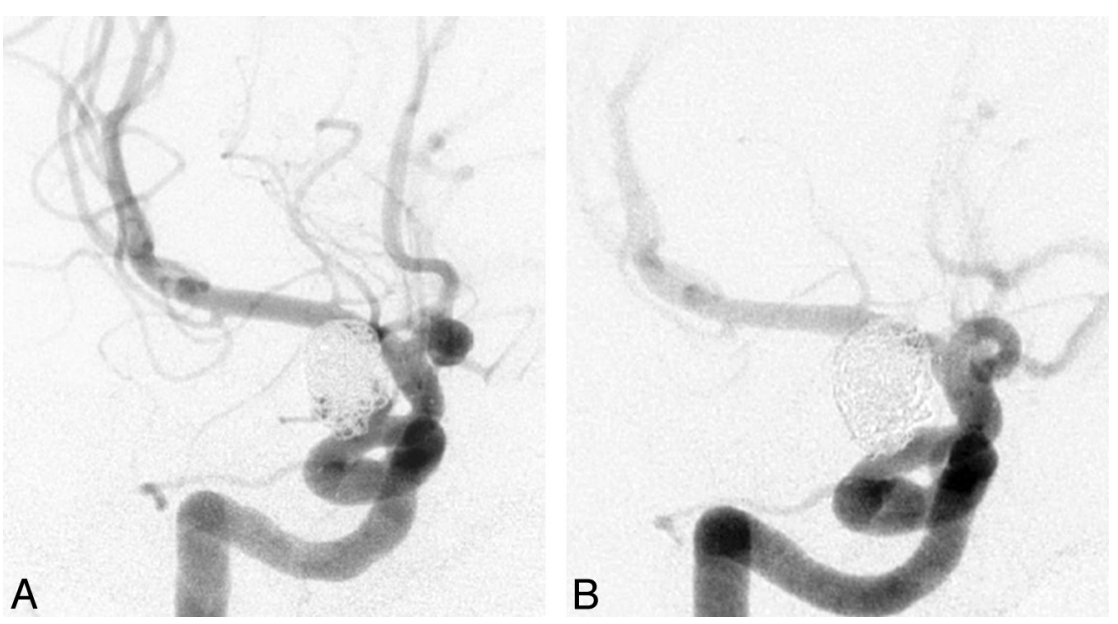

Fig 1. A, A 43-year-old woman with elective coiling of a 9-mm ophthalmic artery aneurysm. Postembolization angiogram shows residual posterior and inferior filling of the lumen. $B$, A 13-month follow-up angiogram shows complete obliteration of the aneurysm lumen.
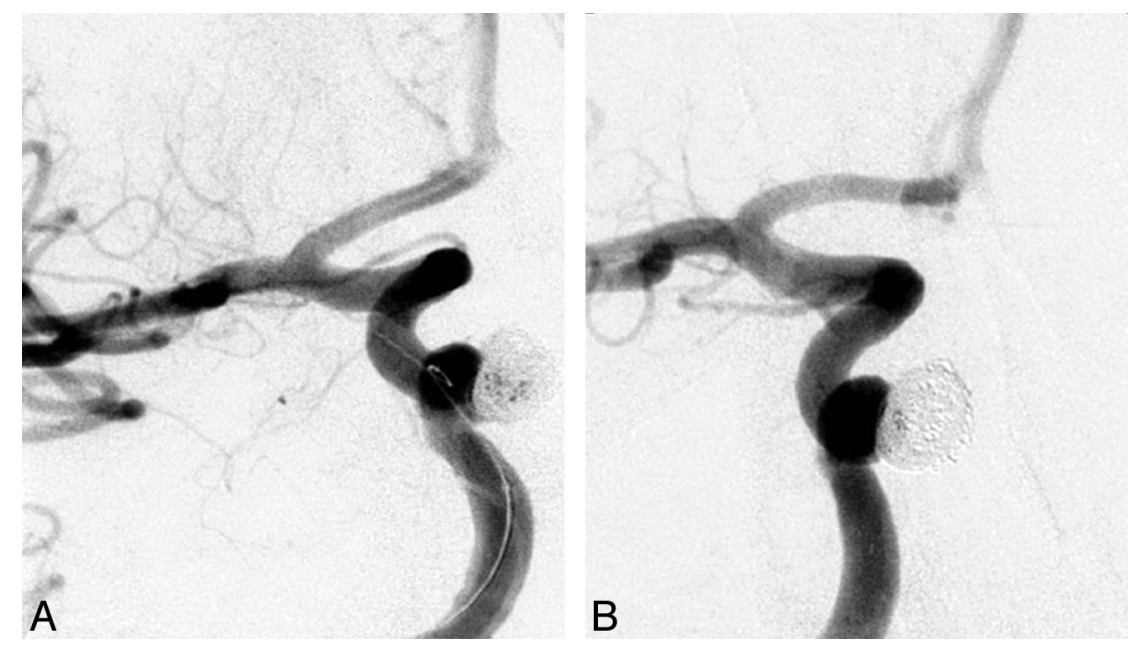

Fig 2. A, A 56-year-old woman with an incidentally discovered 6-mm medially oriented cavernous segment aneurysm with adjacent sphenoid sinus erosion. The procedure required balloon remodeling for a 5.4-mm neck. Immediate postembolization angiogram shows residual aneurysm filling centrally. B, Follow-up angiogram at 20 months shows no aneurysm filling.

and $28.6 \%$ for large aneurysms, without significant difference between the recurrence and nonrecurrence subgroups with respect to overall aneurysm anatomy or percentage HydroCoil used. In the small-aneurysm group, there was improvement in the Roy classification between the initial postembolization appearance and the follow-up angiogram in 21 of 79 cases (26.6\%) with examples shown in Figs 1 and 2. Improvement in the Roy classification was seen in the large-aneurysm group in 11 of 42 cases (26.2\%). In 2 of these cases, there was progressive parent-vessel occlusion following parent-vessel compromise at the time of initial treatment as seen in Fig 3. Tables 4 and 5 summarize the changes in Roy classification for each group and aneurysmobliteration class.

Five patients $(6.3 \%)$ have been retreated in the smallaneurysm group, and 8 patients $(19.0 \%)$, in the large-aneurysm group, for a total of $13(10.7 \%)$ of the 121 patients with angiographic follow-up. Figures 4 and 5 show examples of both small- and large-aneurysm recurrences from our series. 

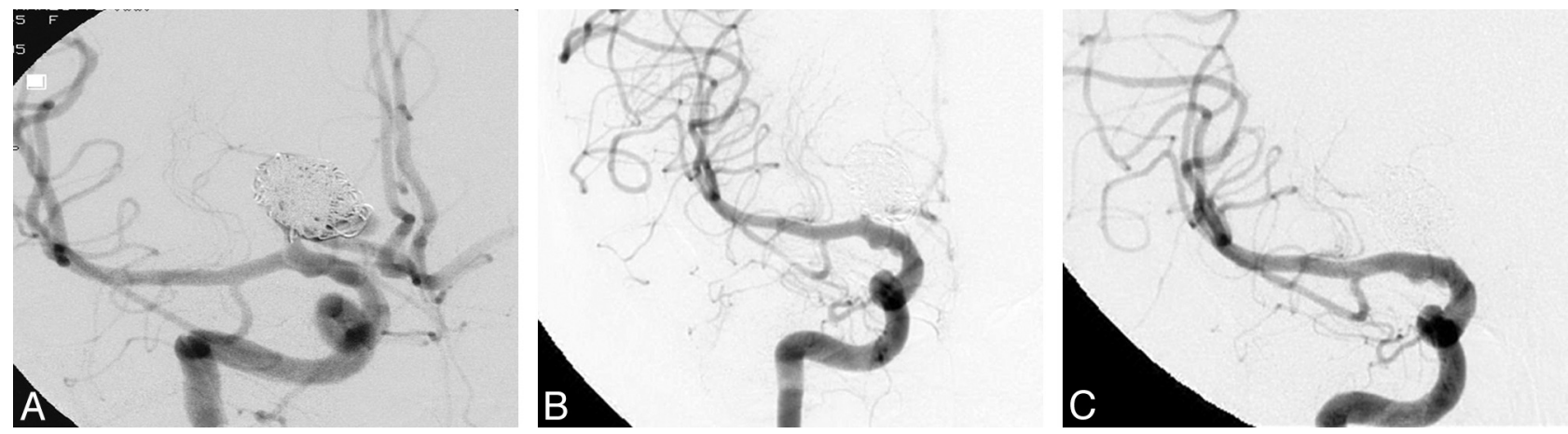

Fig 3. A, A 59-year-old woman with an incidentally discovered 12-mm right $\mathrm{A} 1$ segment anterior cerebral artery aneurysm. Immediate postembolization image shows residual aneurysm filling and coil loops protruding into the parent A1 segment. B, A 6-week surveillance angiogram shows interval obliteration of the aneurysm lumen and diminished flow within the adjacent A1 segment. $C$, A 13-month angiogram shows $A 1$ parent-vessel occlusion and no aneurysm filling.

\begin{tabular}{lccccc}
\hline \multicolumn{2}{l}{ Table 4: Small-aneurysm Roy score distribution for initial result and subsequent follow-up angiograms } & \\
\hline Initial Roy Grade & $\begin{array}{c}\text { No. Aneurysms with } \\
\text { Initial Result (\%) }\end{array}$ & $\begin{array}{c}\text { Class } 1 \text { on Follow-Up } \\
\text { (\%) }\end{array}$ & $\begin{array}{c}\text { Class } 2 \text { on Follow-Up } \\
(\%)\end{array}$ & $\begin{array}{c}\text { Class 3 on Follow-Up } \\
(\%)\end{array}$ & $\begin{array}{c}\text { Recurrence } \\
(\%)\end{array}$ \\
\hline Class 1: complete occlusion & $45(57.0)$ & $35(77.8)$ & $7(15.6)$ & $3(6.7)$ & $10(22.2)$ \\
Class 2: residual neck & $25(31.6)$ & $14(56.0)$ & $9(36.0)$ & $2(8.0)$ & $2(8.0)$ \\
Class 3: residual aneurysm & $9(11.4)$ & $4(44.4)^{*}$ & $3(33.3)$ & $2(22.2)$ & $7(22.2)$ \\
Total & $79(100)$ & $53(67.1)$ & $19(24.1)$ & $14(17.7)$ \\
\hline
\end{tabular}

* One of these 4 patients had parent-vessel occlusion on the follow-up angiogram, which was graded as Roy class 1.

\begin{tabular}{|c|c|c|c|c|c|}
\hline Initial Roy Grade & $\begin{array}{l}\text { No. Aneurysms with } \\
\text { Initial Result (\%) }\end{array}$ & $\begin{array}{c}\text { Class } 1 \text { on Follow-Up } \\
(\%)\end{array}$ & $\begin{array}{c}\text { Class } 2 \text { on Follow-Up } \\
(\%)\end{array}$ & $\begin{array}{c}\text { Class } 3 \text { on Follow-Up } \\
(\%)\end{array}$ & $\begin{array}{c}\text { Recurrence } \\
(\%)\end{array}$ \\
\hline Class 1: complete occlusion & $18(42.9)$ & $11(61.1)$ & $1(5.6)$ & $6(33.3)$ & $7(38.9)$ \\
\hline Class 2: residual neck & $16(38.1)$ & $8(50.0)$ & $6(37.5)$ & $2(12.5)$ & $2(12.5)$ \\
\hline Class 3: residual aneurysm & $8(19.0)$ & $3(37.5)^{*}$ & $0(0)$ & $5(62.5)$ & $3(37.5)$ \\
\hline Total & $42(100)$ & $22(52.4)$ & $7(16.7)$ & $13(31.0)$ & $12(28.6)$ \\
\hline
\end{tabular}

* One of these 3 patients had parent-vessel occlusion on follow-up angiography, which was graded as Roy class 1.
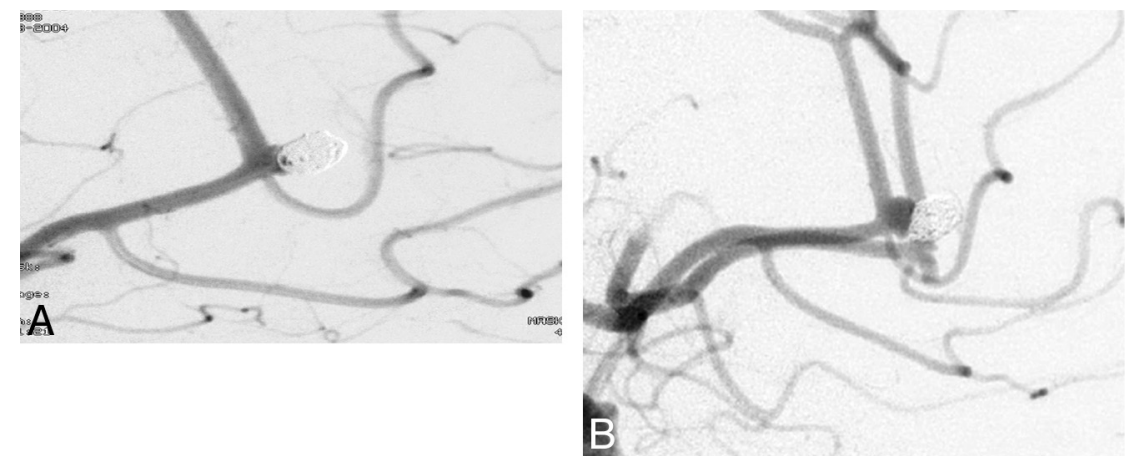

Fig 4. A, A 51-year-old woman with a 5-mm ruptured left pericallosal aneurysm. Postembolization angiogram shows minimal residual aneurysm filling. B, A 2-year angiogram shows significant aneurysm recurrence at the base. This patient had her aneurysm surgically clipped.

\section{Complications}

Thromboembolism. The overall complication rate resulting in permanent neurologic deficit or mortality was $6.0 \%$, with $2.5 \%$ occurring intraprocedurally. There were thromboembolic complications in $15(7.5 \%)$ of the cases, with 8 (16\%) occurring in the first 50 cases and 7 (4.7\%), in the next 150 cases. These resulted in a total of $5(2.5 \%)$ patients with sustained neurologic deficits. Four of these 15 thromboembolic complications occurred on a delayed basis, ranging from postoperative day 1 to day 10 and consisted of symptomatic clot on coil. One patient had delayed ejection of a coil from a right ophthalmic artery aneurysm into the middle cerebral artery
(MCA) bifurcation on postoperative day 1, resulting in MCA occlusion and left upper extremity weakness requiring subsequent endovascular retrieval of the coil. The average degree of parent-vessel compromise for all 15 thromboembolic cases was $35 \%$, by using a standard intracranial measuring technique $^{15}$ on the immediate postembolization images. Additionally, delayed coil migration between immediate postembolism and follow-up angiograms was noted in 4 of these 15 thromboembolic cases, resulting in a further increase of parent-vessel compromise in each case.

Procedural Perforation. There were 8 (4\%) aneurysm perforations: 5 (2.5\%) were asymptomatic, 2 (1\%) resulted in 

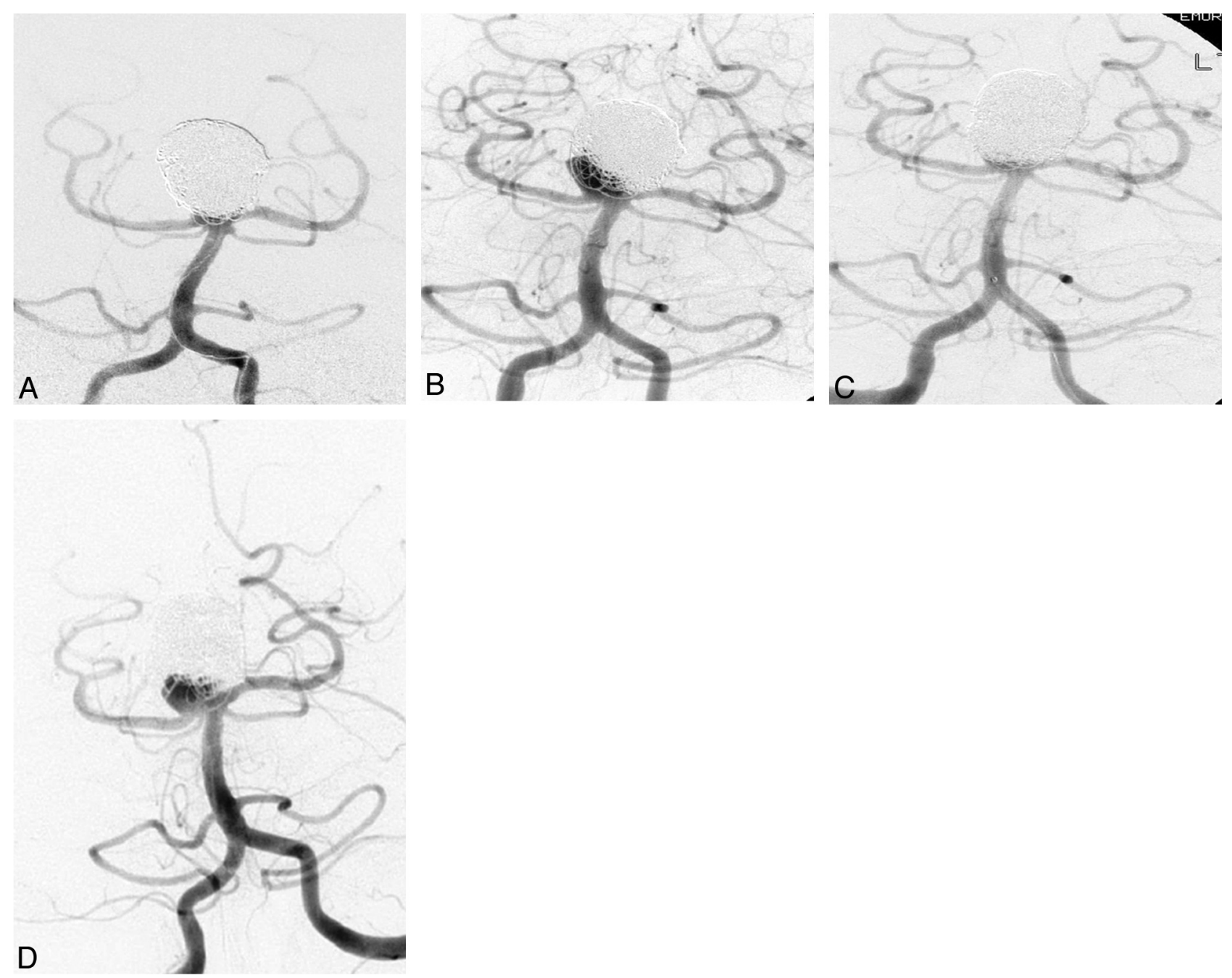

Fig 5. A, A 44-year-old man with a 20-mm basilar tip aneurysm embolized at an outside institution with rapid recanalization. The patient was retreated using this posttreatment angiogram. $B, A$ 10-month follow-up angiogram shows a second recurrence at the right base. $C$, Angiogram obtained immediately following the second retreatment. $D$, A third recurrence at 20 months after the second retreatment in the same location.

severe disability, and $1(0.5 \%)$, in death. There were a total of 5 early hemorrhages in this series. The first was a 75-year-old man with an unruptured 19-mm vertebrobasilar junction aneurysm treated with uneventful stent-assisted coiling. On day 7 , the patient had a massive SAH and died. The second patient was a 45-year-old woman with an unruptured 6-mm aneurysm who underwent uneventful stent-assisted coiling. The same day, she had a sudden deterioration with SAH and negative findings on angiography. She subsequently had several external ventricular drains placed, developed ventriculitis, and died. A 41-year-old man was the third patient with a $21-\mathrm{mm}$ left carotid termination aneurysm who underwent stent-assisted coiling. He was discharged severely disabled after his presentation SAH. Seven months later, he was admitted after a fall and was found to have a large left-sided intracerebral hematoma and died. Rupture of the previously coiled aneurysm could not be excluded, given the location of the hemorrhage.

The fourth patient was a 50-year-old woman with multiple aneurysms previously treated with surgical clipping who underwent coiling of a left ophthalmic aneurysm. Due to deterioration in vision after the coiling, she underwent a craniotomy with optic nerve decompression. She developed a postopera- tive hematoma and died. The fifth patient was a 60 -year-old woman with recanalization of a previously coiled left superior hypophyseal artery aneurysm who underwent stent-assisted retreatment. She presented 3 weeks later with a large parenchymal hemorrhage, herniated, and died.

Hydrocephalus. Hydrocephalus developed in 3 patients $(1.5 \%)$ in our series, all with unruptured aneurysms. Two patients were treated with ventriculoperitoneal shunt and made a full recovery. The third patient with a large basilar tip aneurysm developed hydrocephalus, which was reported from another institution. We have not been able to obtain further information on this patient.

Mass Effect. There were 3 patients who had delayed symptoms of visual tract compression following coiling, with resulting visual changes. Two of these cases involved the large basilar tip aneurysms and resolved completely following steroid therapy. The remaining patient is the one described above with ophthalmic aneurysm mass effect, who had progressive ipsilateral visual loss following coiling of a large ophthalmic artery aneurysm, which did not respond to steroids; she died from hemorrhage following decompressive surgery. 
Vascular Access. There were 4 (2\%) patients who developed large groin hematomas and no permanent morbidity.

\section{Discussion}

This is the largest single-center clinical series on the use of HydroCoil for the treatment intracranial aneurysms, including angiographic follow-up and retreatment data. It describes the first 200 aneurysms, demonstrating the learning curve in an evolving technology with initially stiffer coils (HydroCoil18, and HydroCoil-14), introduction of the softer coils (HydroCoil-10), and the adoption of routine coil steaming for further softening. Many of the aneurysms treated in this series were large and wide-neck, requiring the use of either stent or balloon-assist techniques in $44.5 \%$ of cases. Our definition of recurrence was intentionally stringent, to include any significant deterioration from the baseline postembolization condition for all Roy obliteration classes. Although follow-up was not available for $39.5 \%$ of cases, the primary conclusions from this study demonstrate similar procedural complication rates, favorable recanalization rates, and similar retreatment rates compared with like series of bare platinum coils.

\section{HydroCoil Material Properties}

Bare platinum coils were first introduced in 1991 and have been shown to improve clinical outcome compared with surgical clipping of ruptured intracranial aneurysms. ${ }^{1,16,17}$ There remains limited data regarding the long-term durability of coiling. One major concern is the durability of incompletely treated aneurysms, which occur in the range of 30\%-65.8\% in large clinical series. The relatively high recanalization rate that ranges from $20.9 \%$ to $33.6 \%$ on short- or midterm follow-up angiography $^{18-23}$ remains worrisome as well. This can potentially lead to aneurysm rerupture, though the clinical risk appears to be very low. ${ }^{24}$

The mechanism for aneurysm recanalization is incompletely understood, but clinical and experimental studies strongly suggest that the degree of packing plays a major role in the durability of coiled aneurysms. ${ }^{3,25-28}$ The relationship between aneurysm packing and coil compaction was studied in 145 aneurysms treated with platinum coils with a recanalization rate of $28 \% .^{3}$ Low packing volume was obtained in aneurysms larger than $600 \mathrm{~mm}^{3}$, with average packing of only $16.7 \%$. A strong relationship was found between packing attenuation and coil compaction, with no recurrences in these if the packing volume was $24 \%$ or more. In a study of 62 patients with ruptured intracranial aneurysms, 25.8\% had evidence on follow-up of coil compaction with bare platinum coils. ${ }^{29}$ When the coil-packing ratio was $<50 \%$, the probability of coil compaction was significantly higher.

HydroCoils are made of platinum helical coils coated with a layer of hydrophilic acrylic polymer (hydrogel), which, on contact with blood, causes disentanglement of polymer chains and expansion. ${ }^{30}$ In animal models, treatment with HydroCoils allows relatively denser packing of aneurysms than with bare platinum coils. Histopathologic analysis of HydroCoils implanted in animal models shows minimal inflammatory reaction with a thin layer of fibrous tissue traversing the neck of the aneurysm. ${ }^{4}$ These experimental models showed greater packing attenuation and angiographic durability and less coil compaction with HydroCoil. ${ }^{9,31}$

\section{Immediate Angiographic Results}

The immediate posttreatment angiographic results in this series showed complete obliteration in $53.8 \%$, residual neck in $29.6 \%$, and residual aneurysm filling in $16.6 \%$ of aneurysms. These results compare favorably with the very large series published by Raymond et al, ${ }^{18}$ comprising 501 aneurysms treated with bare platinum coils showing immediate angiographic findings of $35.9 \%$ complete occlusion, $46.3 \%$ with residual neck, and $13.8 \%$ with residual aneurysm filling. Berenstein et $\mathrm{al}^{32}$ noted complete occlusion in $34 \%$, neck remnant in 35\%, and incomplete occlusion in 32\%, in a series of 100 cerebral aneurysms treated with HydroCoils. In our series, there was delayed improvement in aneurysm obliteration (improvement in the Roy class) for $26.6 \%$ of small aneurysms and $26.2 \%$ of large aneurysms, though the use of systemic heparinization during embolization could be a contributing factor. Another study of 33 aneurysms in 30 patients treated with HydroCoils showed complete or near-complete occlusion in $79 \%$ of the aneurysms, ${ }^{5}$ with unsuccessful HydroCoil placement in 2 patients. Follow-up angiograms (3-6 months) were available for 23 of the aneurysms, with $4(17.4 \%)$ aneurysms showing recurrence or coil compaction.

\section{Surveillance Angiography and Recurrence}

We report an overall recurrence rate of $21.5 \%$ for 121 aneurysms followed for a mean of 16.3 months. This is similar to that in other smaller series with overall shorter periods of follow-up. Deshaies et $\mathrm{al}^{8}$ treated 12 aneurysms with HydroCoils, with 6-month follow-up showing interval angiographic stability except for 1 that improved and 1 giant ophthalmic aneurysm that recanalized. In a study of 50 intracranial aneurysms treated with HydroCoils, Gaba et $\mathrm{al}^{10}$ reported a recurrence rate of $17 \%$ at a mean follow-up of 12.3 months. Our overall $21.5 \%$ recurrence rate at 16.3 months of follow-up is in agreement with data from Berenstein et al, ${ }^{32}$ who reported a $21 \%$ recurrence rate for 53 aneurysms followed for a mean of 10.3 months. In contrast, large series of aneurysms treated with bare platinum report recanalization rates from $20.9 \%$ to $33.6 \%{ }^{18,23}$ The aneurysms reported in our series were relatively large (mean, $9.3 \mathrm{~mm}$ ), with many in locations that are known to recanalize frequently such as the ophthalmic $(17.5 \%)$ and basilar tip (18.5\%) regions..$^{21,29,33}$

\section{Delayed Aneurysm Changes}

The follow-up angiograms demonstrated the dynamic nature of endovascular aneurysm treatment, with multiple cases of both improvement and worsening of the initial angiographic result. Delayed coil migration and parent-vessel occlusion were also noted. It is interesting that the percentage of HydroCoil length was higher for the recurrence group than for the nonrecurrence group in both small- and large-aneurysm populations. One potential explanation might be that the relatively stiffer properties of the first-generation HydroCoils might somehow have limited packing in those aneurysms. It will be interesting to compare directly these results with more recently treated aneurysms, incorporating the softer new-generation HydroCoils to see if the recurrence rate will change. 


\section{Retreatment}

Our study yielded an overall retreatment rate of $10.7 \%$, with a $6.3 \%$ rate for small aneurysms and a $19.0 \%$ rate for large aneurysms. This is similar to other published retreatment results for aneurysms treated with bare platinum coils, ranging from $4.9 \%$ to $10 \%$ overall. ${ }^{18,34-36}$

\section{Complications}

The $5.0 \%$ rate of complications of mortality or permanent neurologic morbidity is similar to that in both other HydroCoil series ${ }^{10,32,37}$ and other large series using platinum coils for the treatment of ruptured and unruptured aneurysms, with complication rates ranging from $4 \%$ to $9.3 \% .{ }^{19,21,22,38-40}$ Thromboembolic complications occurred in $7.5 \%$ of the cases and resulted in $2.5 \%$ permanent neurologic deficit. These are similar to complications using only platinum coils, which have been reported in $2.5 \%-11 \%$ of cases. ${ }^{41} \mathrm{With}$ experience and systematic use of aspirin and HydroCoil steaming/softening, thromboembolic events dropped from $16 \%$ in the first 50 cases to $4.7 \%$ during the next 150 cases, similar to the bare platinum coil data. A study of periprocedural thromboembolic events in 191 intracranial aneurysms treated with HydroCoil (the HydroCoil for Endovascular Aneurysm Occlusion [HEAL] study) showed that the incidence was $8.1 \%$, with $2.1 \%$ with permanent symptoms. ${ }^{37}$ For those patients in our series with thromboembolic complications, retrospective analysis frequently showed associated parent-vessel compromise, which likely contributed to the clot on coil. It is our hypothesis that the routine administration of aspirin and increased operator familiarity with the HydroCoils may have contributed to the dramatic overall decrease in thromboembolic complications during the course of this study.

Periprocedural perforation occurred in $8(4 \%)$ of the patients, of which 1 resulted in 1 death $(0.5 \%)$ and 2 , in severe disability (1\%). Three of these aneurysms were unruptured at presentation. Perforation occurred in 3 patients during coiling with bare platinum coils, 3 with HydroCoils, and 2 in which the type of coil placed could not be determined. Our perforation rate is similar to that in bare platinum controls, including a published meta-analysis of 17 retrospective series by Cloft and Kallmes in 2002, ${ }^{42}$ which showed the perforation risk to be $4.5 \%$ for ruptured aneurysms and $0.5 \%$ for unruptured aneurysms. Another bare platinum study showed an overall combined $6.8 \%$ historical risk of procedural perforation. ${ }^{38}$ Comparatively, the perforation rate in the HEAL study was $2.8 \%$ in ruptured aneurysms and $0 \%$ in unruptured aneurysms. ${ }^{37}$ The introduction of the softer HydroCoil-10 system may have a further positive impact in reducing procedural perforations. The initial safety data from the HydroCoil Endovascular Aneurysm Occlusion and Packing Study trial with 249 HydroCoil-treated patients yielded a 3.6\% procedural rupture rate, ${ }^{43}$ perhaps reflecting the potentially increased safety profile of the softer newer generation HydroCoils.

\section{Delayed Complications}

Our series demonstrated a few infrequent temporally delayed complications. There has been previously documented concern regarding aseptic meningitis following HydroCoil treatment of unruptured intracranial aneurysms, ${ }^{6,44}$ which occurred in $1.5 \%$ of patients in this series. The pathophysiology of this phenomenon is currently unknown, but the condition seems to respond well to steroids or ventricular shunt surgery. Other delayed complications include a $1.5 \%$ incidence of symptomatic visual loss resulting from mass effect from large coiled aneurysms immediately adjacent to the visual tracts, which has also been previously described ${ }^{45}$ and is not unique to HydroCoils. Finally, of the 15 patients in our series with thromboembolic complications, 4 had delayed coil migration resulting in increased measurable parent-vessel compromise.

\section{Limitations and Future Direction}

The primary limitations of this study are its retrospective nature and a midterm 16.3-month period of angiographic follow-up. Additionally, follow-up was not available for $39.5 \%$ of patients. However, the quality of both clinical and imaging documentation has provided what we believe is an accurate assessment of our experience. There were no strict inclusion and exclusion criteria, and HydroCoil usage was left to the preference of the surgeon. The patient demographics, aneurysm size, and aneurysm configuration reported in this series are typical of our overall practice as a whole and would mitigate against systemic selection bias. We are currently conducting an evaluation of our more recently treated patients, which will include the softer HydroCoil-10 system as well as the more recently introduced HydroSoft finishing coils. A randomized controlled trial and a prospective registry will also contribute longer term data regarding treatment efficacy and permanence with these materials. ${ }^{37}$

\section{Conclusions}

These initial 200 consecutive aneurysms treated with HydroCoil demonstrate similar complication rates compared with historical series using pure platinum coils. Follow-up data were available for $60.5 \%$ of patients during a mean of 16.3 months, indicating favorable recanalization rates and similar retreatment rates compared with published pure platinum coil studies. Our institutional data are also comparable with several smaller HydroCoil series and would support the safety and midterm durability of hydrogel-coated aneurysm coils in the treatment of cerebral aneurysms.

\section{References}

1. Molyneux A, Kerr R, Stratton I, et al. International Subarachnoid Aneurysm Trial (ISAT) of neurosurgical clipping versus endovascular coiling in 2143 patients with ruptured intracranial aneurysms: a randomised trial. Lancet 2002;360:1267-74

2. Derdeyn CP, Barr JD, Berenstein A, et al. The International Subarachnoid Aneurysm Trial (ISAT): a position statement from the Executive Committee of the American Society of Interventional and Therapeutic Neuroradiology and the American Society of Neuroradiology. AJNR Am J Neuroradiol 2003;24:1404-08

3. Sluzewski M, van Rooij WJ, Slob MJ, et al. Relation between aneurysm volume, packing, and compaction in 145 cerebral aneurysms treated with coils. Radiology 2004;231:653-58

4. Kallmes DF, Fujiwara NH. New expandable hydrogel-platinum coil hybrid device for aneurysm embolization. AJNR Am J Neuroradiol 2002;23:1580-88

5. Arthur AS, Wilson SA, Dixit S, et al. Hydrogel-coated coils for the treatment of cerebral aneurysms: preliminary results. Neurosurg Focus 2005;18:E1

6. Brisman JL, Song JK, Niimi Y, et al. Treatment options for wide-necked intracranial aneurysms using a self-expandable hydrophilic coil and a self-expandable stent combination. AJNR Am J Neuroradiol 2005;26:1237-40

7. Cloft HJ, Kallmes DF. Aneurysm packing with HydroCoil Embolic System versus platinum coils: initial clinical experience. AJNR Am J Neuroradiol 2004;25:60-62

8. Deshaies EM, Bagla S, Agner C, et al. Determination of filling volumes in $\mathbf{H y}$ - 
droCoil-treated aneurysms by using three-dimensional computerized tomography angiography. Neurosurg Focus 2005;18:E5

9. Ding YH, Dai D, Lewis DA, et al. Angiographic and histologic analysis of experimental aneurysms embolized with platinum coils, Matrix, and HydroCoil. AJNR Am J Neuroradiol 2005;26:1757-63

10. Gaba RC, Ansari SA, Roy SS, et al. Embolization of intracranial aneurysms with hydrogel-coated coils versus inert platinum coils: effects on packing density, coil length and quantity, procedure performance, cost, length of hospital stay, and durability of therapy. Stroke 2006;37:1443-50

11. Gunnarsson T, Klurfan P, terBrugge KG, et al. Treatment of intracranial aneurysms with hydrogel coated expandable coils. Can J Neurol Sci 2007;34:38-46

12. Hunt WE, Hess RM. Surgical risk as related to time of intervention in the repair of intracranial aneurysms. J Neurosurg 1968;28:14-20

13. Kistler JP, Crowell RM, Davis KR, et al. The relation of cerebral vasospasm to the extent and location of subarachnoid blood visualized by CT scan: a prospective study. Neurology 1983;33:424-36

14. Roy D, Milot G, Raymond J. Endovascular treatment of unruptured aneurysms. Stroke 2001;32:1998-2004

15. Chimowitz MI, Lynn MJ, Howlett-Smith H, et al. Comparison of warfarin and aspirin for symptomatic intracranial arterial stenosis. $N$ Engl $\mathrm{J} \mathrm{Med}$ 2005;352:1305-16

16. Guglielmi G, Vinuela F, Dion J, et al. Electrothrombosis of saccular aneurysms via endovascular approach. Part 2. Preliminary clinical experience. J Neurosurg 1991;75:8-14

17. Guglielmi G, Vinuela F, Sepetka I, et al. Electrothrombosis of saccular aneurysms via endovascular approach. Part 1 . Electrochemical basis, technique, and experimental results. J Neurosurg 1991;75:1-7

18. Raymond J, Guilbert F, Weill A, et al. Long-term angiographic recurrences after selective endovascular treatment of aneurysms with detachable coils. Stroke 2003;34:1398-403

19. Henkes H, Fischer S, Weber W, et al. Endovascular coil occlusion of 1811 intracranial aneurysms: early angiographic and clinical results. Neurosurgery 2004;54:268-80, discussion 280-85

20. Koivisto T, Vanninen R, Hurskainen H, et al. Outcomes of early endovascular versus surgical treatment of ruptured cerebral aneurysms: a prospective randomized study. Stroke 2000;31:2369-77

21. Sluzewski M, van Rooij WJ, Rinkel GJ, et al. Endovascular treatment of ruptured intracranial aneurysms with detachable coils: long-term clinical and serial angiographic results. Radiology 2003;227:720-24

22. Ng P, Khangure MS, Phatouros CC, et al. Endovascular treatment of intracranial aneurysms with Guglielmi detachable coils: analysis of midterm angiographic and clinical outcomes. Stroke 2002;33:210-17

23. Murayama Y, Nien YL, Duckwiler G, et al. Guglielmi detachable coil embolization of cerebral aneurysms: 11 years' experience. J Neurosurg 2003;98: 959-66

24. CARAT Investigators. Rates of delayed rebleeding from intracranial aneurysms are low after surgical and endovascular treatment. Stroke 2006;37:143742. Epub 2006 Apr 20

25. Reul J, Weis J, Spetzger U, et al. Long-term angiographic and histopathologic findings in experimental aneurysms of the carotid bifurcation embolized with platinum and tungsten coils. AJNR Am J Neuroradiol 1997;18:35-42

26. Kawanabe Y, Sadato A, Taki W, et al. Endovascular occlusion of intracranial aneurysms with Guglielmi detachable coils: correlation between coil packing density and coil compaction. Acta Neurochir (Wien) 2001;143:451-55

27. Groden C, Laudan J, Gatchell S, et al. Three-dimensional pulsatile flow simulation before and after endovascular coil embolization of a terminal cerebral aneurysm. J Cereb Blood Flow Metab 2001;21:1464-71
28. Reul J, Spetzger U, Weis J, et al. Endovascular occlusion of experimental aneurysms with detachable coils: influence of packing density and perioperative anticoagulation. Neurosurgery 1997;41:1160-65, discussion 1165-68

29. Kai Y, Hamada J, Morioka M, et al. Evaluation of the stability of small ruptured aneurysms with a small neck after embolization with Guglielmi detachable coils: correlation between coil packing ratio and coil compaction. Neurosurgery 2005;56:785-92, discussion 785-92

30. Canton G, Levy DI, Lasheras JC. Changes in the intraaneurysmal pressure due to HydroCoil embolization. AJNR Am J Neuroradiol 2005;26:904-07

31. Yoshino Y, Niimi Y, Song JK, et al. Endovascular treatment of intracranial aneurysms: comparative evaluation in a terminal bifurcation aneurysm model in dogs. J Neurosurg 2004;101:996-1003

32. Berenstein A, Song JK, Niimi Y, et al. Treatment of cerebral aneurysms with hydrogel-coated platinum coils (HydroCoil): early single-center experience. AJNR Am I Neuroradiol 2006;27:1834-40

33. Vallee JN, Aymard A, Vicaut E, et al. Endovascular treatment of basilar tip aneurysms with Guglielmi detachable coils: predictors of immediate and long-term results with multivariate analysis 6-year experience. Radiology 2003;226:867-79. Epub 2003 Jan 24

34. Pandey AS, Koebbe C, Rosenwasser RH, et al. Endovascular coil embolization of ruptured and unruptured posterior circulation aneurysms: review of a 10year experience. Neurosurgery 2007;60:626-36, discussion 636-37

35. Renowden SA, Koumellis P, Benes V, et al. Retreatment of previously embolized cerebral aneurysms: the risk of further coil embolization does not negate the advantage of the initial embolization. AJNR Am J Neuroradiol 2008;29: 1401-04. Epub 2008 Apr 24

36. Slob MJ, Sluzewski M, van Rooij WJ, et al. Additional coiling of previously coiled cerebral aneurysms: clinical and angiographic results. AJNR Am J Neuroradiol 2004;25:1373-76

37. Cloft HJ. HydroCoil for Endovascular Aneurysm Occlusion (HEAL) study: periprocedural results. AJNR Am J Neuroradiol 2006;27:289-92

38. Park HK, Horowitz M, Jungreis C, et al. Periprocedural morbidity and mortality associated with endovascular treatment of intracranial aneurysms. AJNR Am J Neuroradiol 2005;26:506-14

39. Raftopoulos C, Mathurin $\mathrm{P}$, Boscherini D, et al. Prospective analysis of aneurysm treatment in a series of 103 consecutive patients when endovascular embolization is considered the first option. J Neurosurg 2000;93:175-82

40. Bavinzski G, Killer M, Gruber A, et al. Treatment of basilar artery bifurcation aneurysms by using Guglielmi detachable coils: a 6-year experience. J Neurosurg 1999;90:843-52

41. Workman MJ, Cloft HJ, Tong FC, et al. Thrombus formation at the neck of cerebral aneurysms during treatment with Guglielmi detachable coils. AJNR Am J Neuroradiol 2002;23:1568-76

42. Cloft HJ, Kallmes DF. Cerebral aneurysm perforations complicating therapy with Guglielmi detachable coils: a meta-analysis. AJNR Am J Neuroradiol 2002;23:1706-09

43. White PM, Lewis SC, Nahser H, et al. HydroCoil Endovascular Aneurysm Occlusion and Packing Study (HELPS trial): procedural safety and operatorassessed efficacy results. AJNR Am J Neuroradiol 2008;29:217-23

44. Meyers PM, Lavine SD, Fitzsimmons BF, et al. Chemical meningitis after cerebral aneurysm treatment using two second-generation aneurysm coils: report of two cases. Neurosurgery 2004;55:1222

45. Pickett GE, Laitt RD, Herwadkar A, et al. Visual pathway compromise after HydroCoil treatment of large ophthalmic aneurysms. Neurosurgery 2007;61: E873-874 